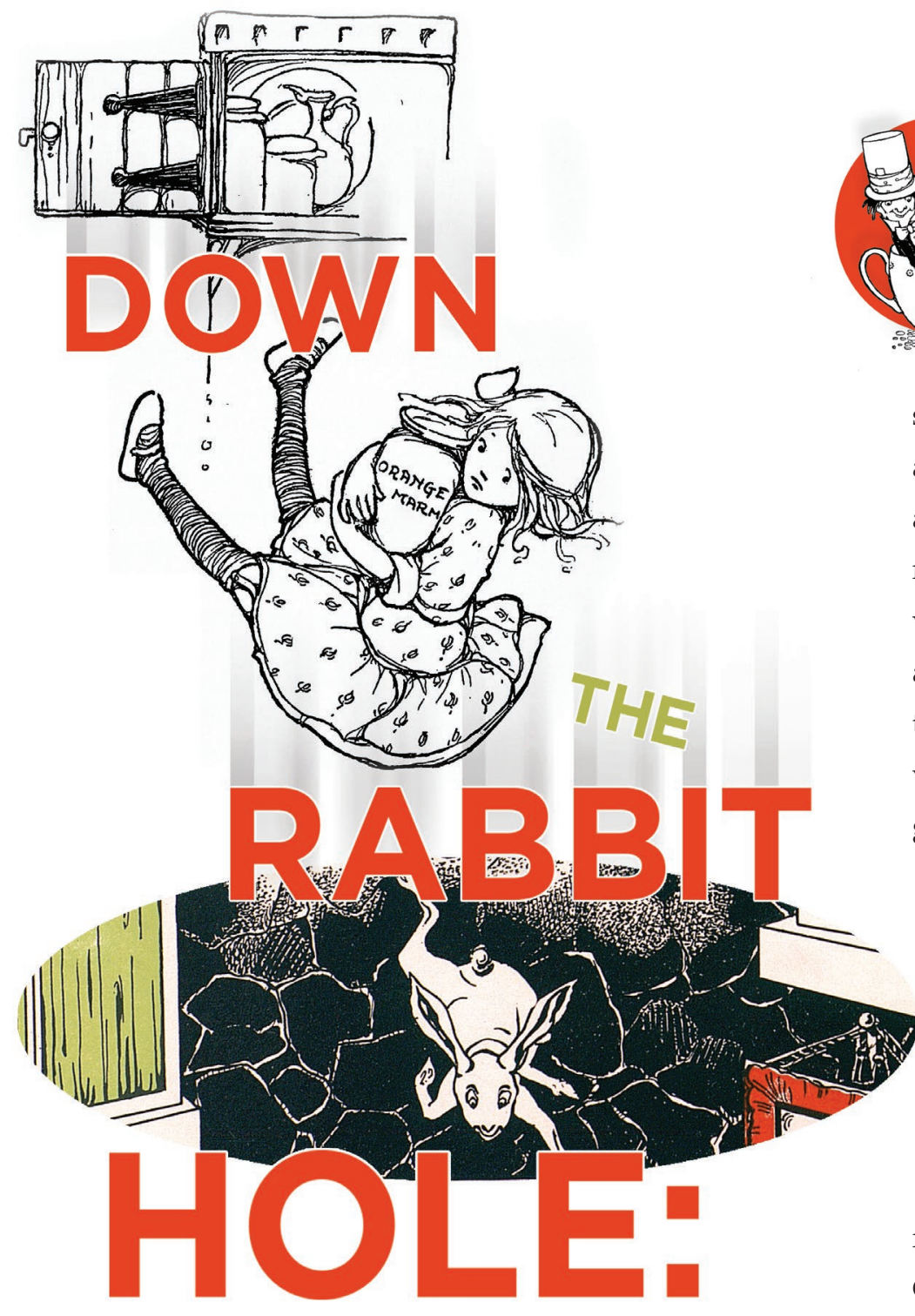

\title{
Researching the Golden Age of Children's Literature in the Baldwin
}

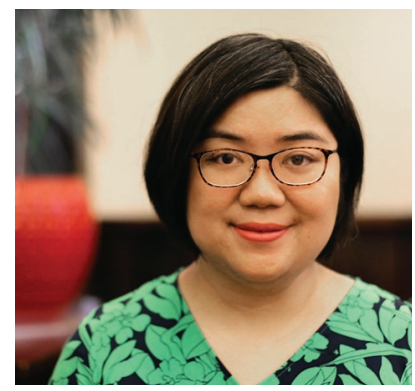

\section{BY RAE X. YAN, PhD}

\section{ASSISTANT PROFESSOR}

of English in British

Literature 1830-1900

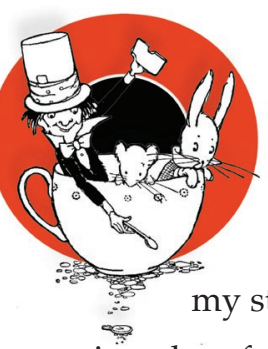

n the first day of my Fall 2018 course on the Golden Age of Children's Literature, I polled signed up for a study of the "Golden Age," an admittedly crustier historical period of British and American children's literature from the mid-1800s to early-1900s centered around writers such as L. Frank Baum, Lewis Carroll, and A. A. Milne. I fully expected students to discuss their nostalgia for the Disneyfied versions of the characters at the heart of the genre-Mowgli and Baloo, Peter Pan and

Wendy, and, of course, good old Pooh and Piglet. While a good number of my students expressed their interest in reconnecting with these classic characters, many more discussed their curiosity about another central part the course: a final project involving research in the Baldwin Library of Historical Children's Literature here at the University of Florida.

For this final project, I asked students to explore the Baldwin's vast collection of 120,000 historical children's texts (including issues of children's literary magazines such as The Brownies' Book and St. Nicholas Magazine) and compose a scholarly introduction for a work that sparked their interest from the collection. This prospect of adventuring, like a troupe of Alices, into the world of the Baldwin collection to bring back new stories about children's literature turned out to be the

ABOve, ALICE: Alice in Wonderland. Mabel Lucie Attwell (c.1910) ABOve, RABBit: Alice's Adventures in Wonderland. Blanche McManus (c.1899) Above, Mad hatter: Alice in Wonderland. Mabel Lucie Attwell (c.1910) 


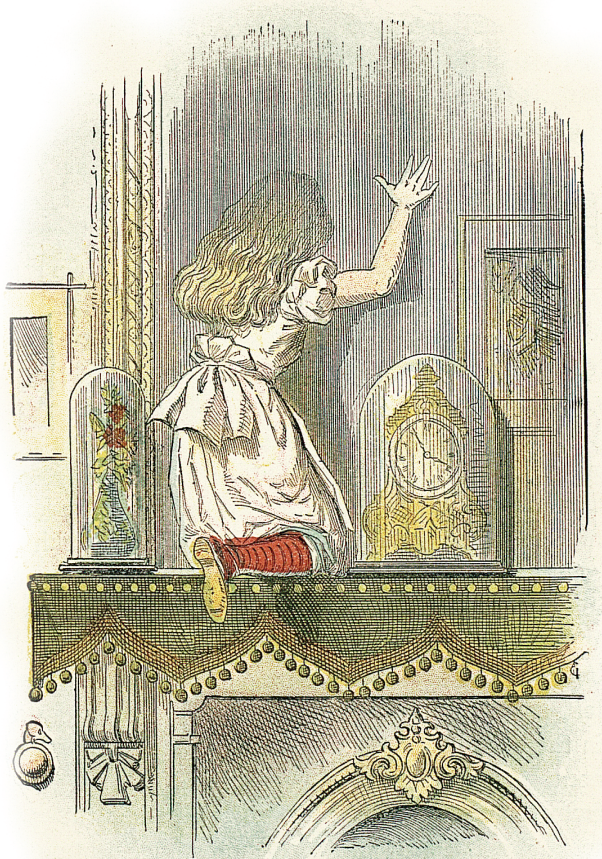

most exciting venture

for many of the

students in the course.

The process was

entirely new to many

of them. Scholarly

introductions com-

posed by literary

critics often provide

first-time readers

with background

contexts that aid

readers' understandings of the text. In order to write such a scholarly introduction, students needed to conduct literary analyses of their primary texts alongside research into the biographical, historical and theoretical connections behind these works of children's literature.

The four scholarly introductions featured in this issue of SOURCE by Hugh Hickman, Chloe Kuka, Sofia Padrón, and Tiffany Teska were produced with research assistance from Suzan Alteri, the curator of the Baldwin Library, and research librarians on campus, including Jeanne Ewert, the subject specialist for English and American Literature. These introductions were selected for this issue of SOURCE and published in full on the UF Digital Collections because of the ways they spoke to each other, and for their multi-layered approaches to thinking about the historical children's literary works that we encountered in the Baldwin Library.

Mr. Hickman's "Isabel Frances Bellows"

'A Deadly Feud' and the Cultural Confines of the Duel and the Police" and Ms. Kuka's "Work and Play: The Finger Plays of Edith Goodyear Alger" are scholarly introductions that recover and reflect on the significance of poetry for children commonly found in children's literary magazines like St. Nicholas. The poems Mr. Hickman and Ms. Kuka examine initially appear

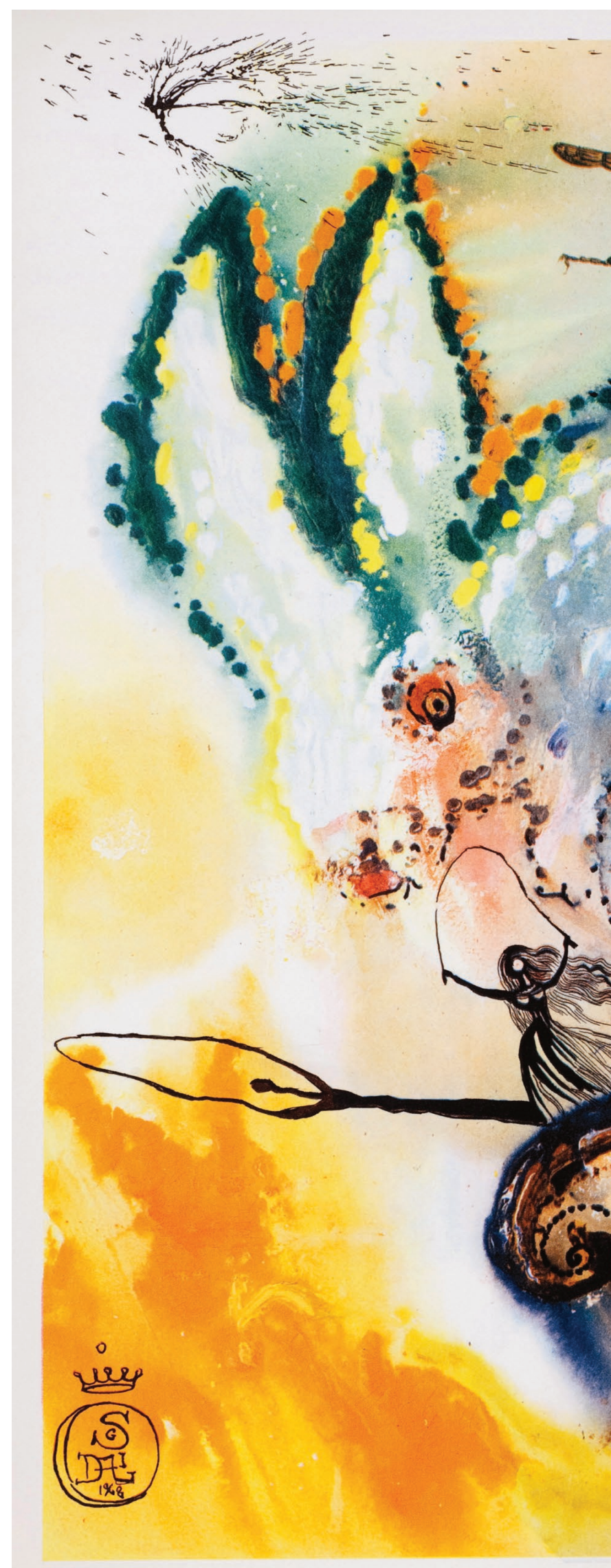

TOP LEFT: Through the Looking-Glass, and What Alice Found There. John Tenniel (1899) 


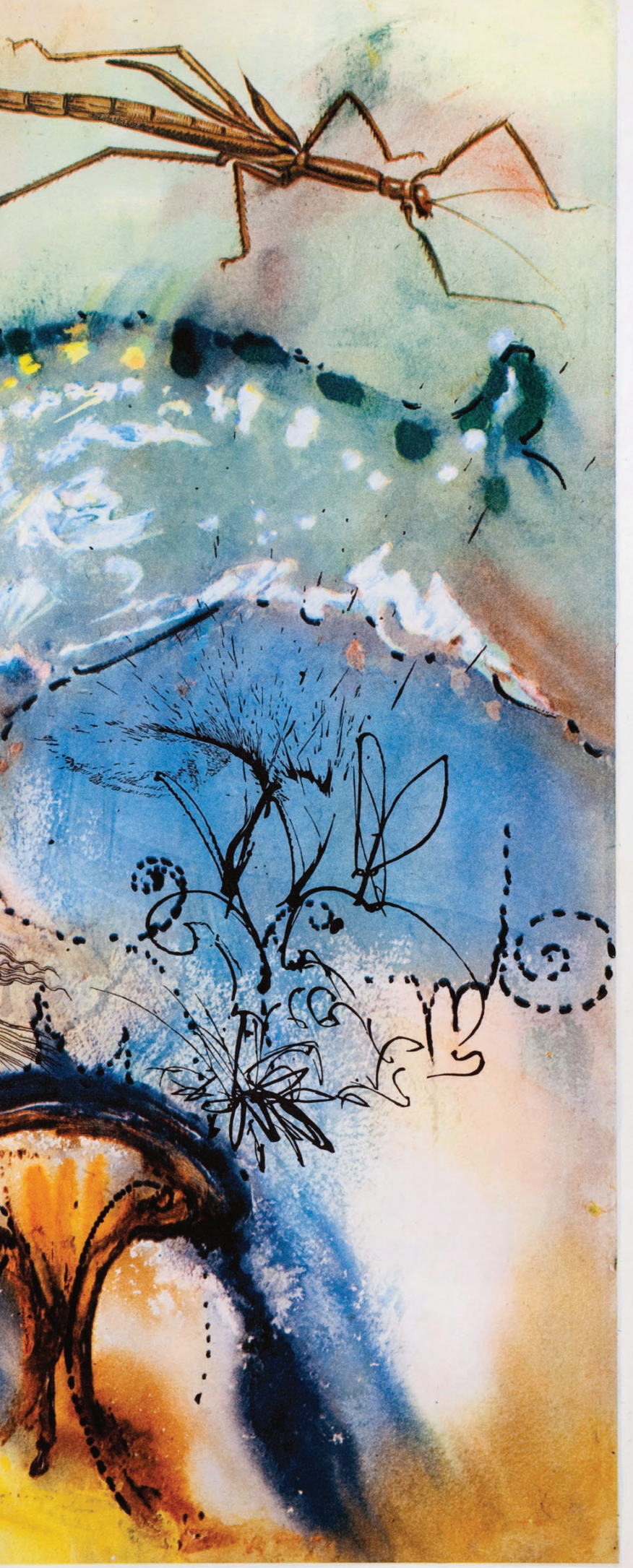

benign in their depictions of seemingly humdrum worlds: those of bees and fleas, washing days and finger plays. However, Mr. Hickman reveals how the poem "The Deadly Feud," a simple jingle about insects, can directly transmit a series of sharp cultural lessons about the place of violence and policing in 19th-century American culture. Ms. Kuka's essay, too, strikingly illuminates the educational theories of Friedrich Froebel, the founder of the kindergarten movement, and Mary Mapes Dodge, the influential editor of St. Nicholas Magazine, that underlie Goodyear's magnificent visual poems.

Ms. Padrón's “Checkmate: Sources of Power in Alice's Adventures in Wonderland" and Ms. Teska's "The Dream World of Wonderland" are two projects that recontextualize Carroll's classic Alice's Adventures in Wonderland by comparing and contrasting the narrative text against bold illustrations of Carroll's story by the infamous Surrealist artist Salvador Dalí for the 1969 Maecenas Press-Random House edition of Alice. In Ms. Padrón's introduction, Alice locates four forms power takes in Wonderland and the ways in which these forms of power become exaggerated and even challenged in Dalí's depictions of infamous Wonderland characters, such as the Queen of Hearts. Ms. Teska's study of Alice reflects on the biographical and theoretical connections linking together Carroll, Dalí, and the psychoanalyst Sigmund Freud as three major figures equally intrigued by the significant role of dreaming and unconscious desire in the production of art.

In the process of developing their scholarly introductions, many students commented on how the project helped them to synthesize their academic and personal interests. Most of the projects for the course drew on students' past knowledge and practices in courses as diverse as art history, comic studies, education, political science, and psychology - and even individual studies outside academic settings in Arabic, fairytales, and the history of World War I. 
